\title{
Original article (short paper) \\ Association between Physical Activity and Disability in patients with low back pain
}

\author{
Cristian Douglas Dantas de Sousa \\ Ana Carla Lima Nunes \\ Fabianna Resende de Jesus-Moraleida \\ Universidade Federal do Ceará, Fortaleza, CE, Brazil
}

\begin{abstract}
Aims: Physical activity levels could be related to chronic low back pain (LBP) in those who suffer from it; thus the purpose of this study was yo describe the physical activity levels in patients with chronic LBP, and to investigate whether physical activity levels are associated with LBP related disability and pain intensity in them. Methods: This is a cross-sectional study with 36 patients with chronic LBP, both sexes, aged between 18 and 70 years. The main outcomes evaluated in this study were physical activity levels, LBP-related disability and pain intensity. Results: Participants were predominantly classified as active (53\%) and irregularly active (42\%). Mean pain intensity was $4.81( \pm 2.72)$ points, while mean LBP-related disability was $13.19( \pm 6.95)$. Physical activity and disability were negative and moderately correlated. Conclusion: Physical activity and disability were inversely associated, indicating that patients with chronic LBP that have lower physical activity levels had higher levels of disability with chronic LBP lower physical activity levels are associated with higher levels of disability.
\end{abstract}

Keywords: low back pain, motor activity, disability evaluation.

\section{Introduction}

Chronic low back pain (LBP) has been identified as the main complaint among Brazilian people with musculoskeletal disorders ${ }^{1}$, with prevalence rates ranging from $37.8 \%$ to $61.4 \%$ in adults, and up to $56 \%$ in the elderly population ${ }^{2}$. Low physical activity levels and sedentary lifestyle are among possible contributing causes for its occurrence ${ }^{3}$. Still, although being physically active is encouraged in patients with this complaint, the evidence of its association with LBP-related disability pathway needs to be further explored ${ }^{4,5}$. According to the proposed Fear Avoidance Behavior Model of Pain ${ }^{6}$, patients with LBP can show different activity-related behavioral strategies when confronted with pain. While some react with an endurance behavior, persisting in performing usual activities despite pain, others react with an avoidance behavior, avoiding activities due to fear of reinjury ${ }^{6,7}$. This could eventually result in both a decrease in the levels of physical activities and an increase in the level of disability ${ }^{7}$. Considering that being physically inactive is an endemic problem worldwide and contributes to increasing the burden of several chronic health conditions ${ }^{8}$, there is a need to clarify the relationship between physical activity level and pain intensity and related disability in those who suffer from chronic $\mathrm{LBP}^{3,4}$. Thus, the objective of this study was to describe the physical activity levels in individuals with chronic LBP and to investigate wether this factor is associated with the pain intensity and related disability.

\section{Methods}

\section{Study characteristics and Participants}

This is a pilot study that takes part of a larger ongoing research project entitled "Movimento", which was conducted in a low income area of the Northeast of Brazil. This project aims managing patients from primary care center ANASTÁCIO MAGALHÃES with chronic pain complaints. We conducted this cross-sectional design study in the Human Movement Analysis Laboratory of the Department of Physiotherapy, at Universidade Federal do Ceará (UFC), Brazil, between July and November 2015. For sample size purposes, we calculated that it would be necessary to include 36 participants in order to obtain a statistical power of $80 \%$ to detect a moderate correlation of $\mathrm{r}=0.30$ between physical activity and disability ${ }^{9}$. To be included in the study, individuals were from both sexes, aged between 18 and 70 years, residents from the district in which the community center was based, with a primary complaint of chronic LBP. This condition was defined as continuously or recurrently pain for more than three months in the region located below the costal margin and above the line of the gluteal fold, with or without the presence of irradiation to the leg ${ }^{10}$. Participants were excluded from the study when not having chronic LBP as their main complaint, if they have had recent surgeries and those with serious hearing or cognitive deficits that prevented them from answering to questionnaires. Those who agreed to participate in the study signed the informed consent form. The documents required for the inclusion of this project have been submitted, considered and approved by the Human Research Ethics Committee - CEP UFC (Opinion no. 1,086,403/2015).

\section{Recruitment procedure and Outcome}

Before data collection, all involved researchers were trained in order to standardize the method of application of the instruments. First, we collected socio-demographic identification data, clinical data and characteristics of pain, as well as information on the regular practice or not of physical exercise, according 
to the World Health Organization (WHO) recommendations ${ }^{11}$. The outcome variables evaluated in this study were: physical activity levels, LBP-related disability and pain intensity.

We measured self- reported physical activity levels by both the categories and continuous score of Brazilian version of the International Physical Activity Questionnaire Short Form $(\text { IPAQ })^{12}$. Its short version consists of seven open questions that allow us to estimate the time spent per week in four areas, namely: vigorous activity, moderate activities, displacement and time spent at rest (sitting or lying). We used the interpretation of results to categorize participants as "very active," "active," "irregularly active" and "sedentary" 13,14 . We also calculated the total Metabolic Equivalent Task (MET) as established in the IPAQ manual to correlate physical activity levels with pain intensity and disability. For this purpose, we computed METs values for walking (3.3 METs X minute walk X days of walking), moderate intensity activity (4.0 METs X minute walk X days walk) and vigorous intensity activity (8.0 METs X minute walk $\mathrm{X}$ days of walking). Then, we calculated total physical activity given in MET-minutes/week by adding up the walk activities + activities moderate + vigorous activities ${ }^{15}$.

We measured LBP-related disability with the Roland-Morris Disability Questionnaire (RMDQ), which consists of 24 questions that verify disability as a result of LBP, relating to the activities of daily living, pain and function. The higher the score, the higher the perception of patients regarding the disability ${ }^{16}$. Finally, we recorded participants' perceived pain intensity at the time of assessment, by means of the numerical rating scale (NRS), using numbers from 0 to 10 in which the level 0 (zero) represents no pain and level 10 (ten) is the worst possible pain ${ }^{17}$.

\section{Statistics}

We verified data normality by means of the Shapiro-Wilk test. All variables were not normally distributed, except for the continuous variable LBP-related disability (RMDQ continuous score). Thus, we used measures of central tendency (mean/median), dispersion (standard deviation/interquartile) and relative frequency (\%) to describe the clinical, sociodemographic and functional characteristics of the study participants. In order to verify the correlation between physical activity level and disability, in addition to the correlation between physical activity level and the pain intensity, we used the Spearman correlation test. We later considered cutoff point values for correlation scores proposed by Cohen ${ }^{9}$, that is, 0.10 weak, 0.3 moderate, and 0.5 large. Statistical analyzes were performed using SPSS, version 20.0, with $\alpha$ level set at 0.05 .

\section{Results}

Among the 68 individuals recruited, 32 were later excluded for not fitting into the study criteria. Thus, the final sample was composed of 36 participants (Figure 1).

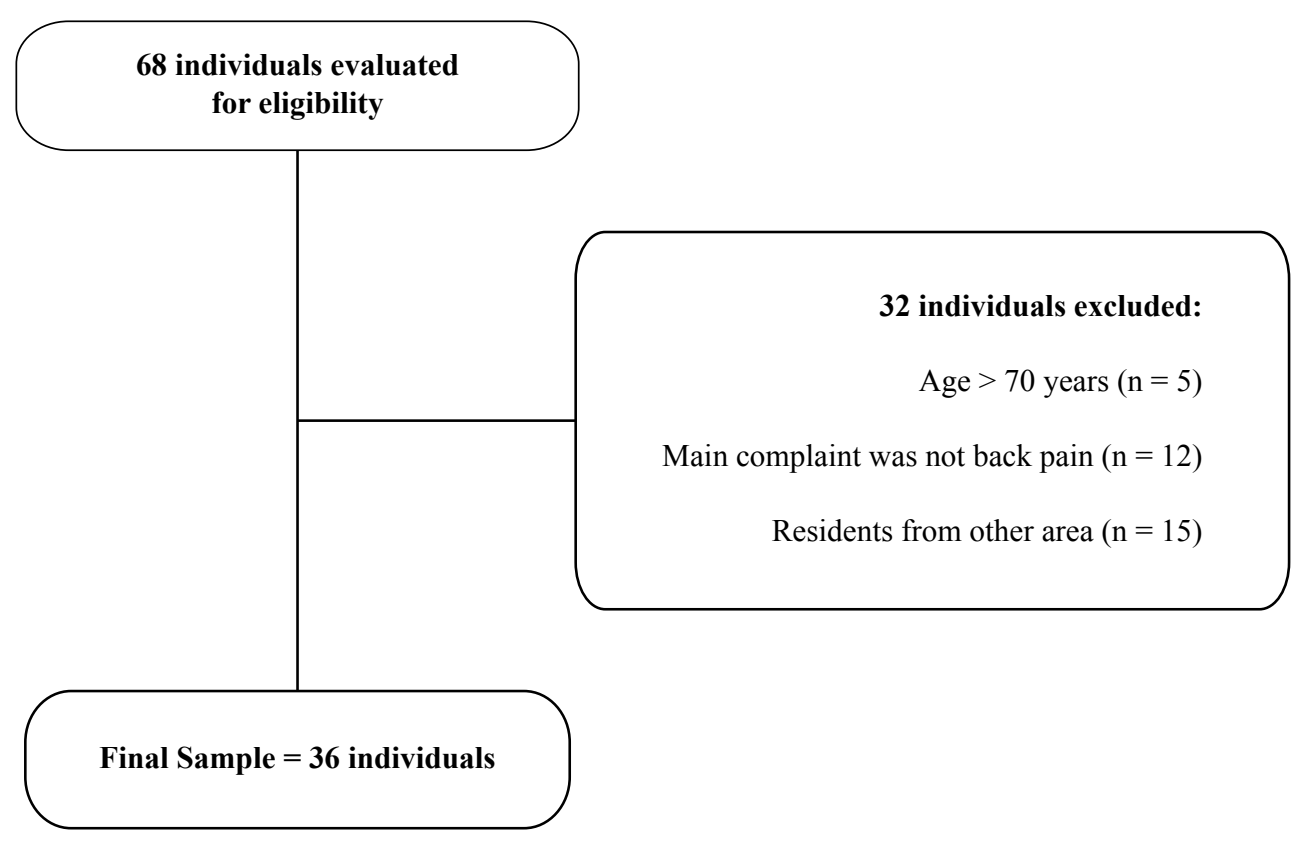

Figura 1 - "Sample constitution flowchart"

Table 1 shows the characteristics of the sample. The mean age of the participants was 52.14 years $( \pm 13.76$ years), and the majority of them consisted of females $(83 \%)$. The results also showed that $69 \%$ of individuals did not practice regular physical exercise and their mean body mass index (BMI) was
28.15 ( \pm 5.86$)$, which is considered to be overweight. Most individuals reported that their complaint had an insidious onset (50\%); 36\% showed duration of pain between six and ten years. Their reported median pain intensity was 5.50 points, while the reported disability was $13.19( \pm 6.95)$ points (Table 1$)$. 
Table 1 - Sociodemographic and clinical characteristics of individuals with chronic low back pain, Fortaleza - CE, Brazil, 2016. ( $\mathrm{n}=36$ )

\begin{tabular}{|c|c|}
\hline Variable & $\mathbf{N}(\%)$ \\
\hline Age (mean \pm SD) & $52.14 \pm 13.76$ \\
\hline BMI (mean \pm SD) & $28.15 \pm 5.86$ \\
\hline \multicolumn{2}{|c|}{ Sex } \\
\hline $\begin{array}{c}\text { Female } \\
\text { Male }\end{array}$ & $\begin{array}{c}30(83) \\
6(17)\end{array}$ \\
\hline \multicolumn{2}{|c|}{ Marital status } \\
\hline $\begin{array}{l}\text { Single } \\
\text { Married } \\
\text { Divorced } \\
\text { Widower }\end{array}$ & $\begin{array}{l}12(33) \\
14(39) \\
6(17) \\
4(11)\end{array}$ \\
\hline Engaged in physical exercise & $11(31)$ \\
\hline \multicolumn{2}{|c|}{ Education level } \\
\hline $\begin{array}{c}\text { Illiterate } \\
\text { Elementary School } \\
\text { High School } \\
\text { Higher educational degree (graduation/post graduation) }\end{array}$ & $\begin{array}{l}4(11) \\
11(31) \\
16(44) \\
5(14)\end{array}$ \\
\hline \multicolumn{2}{|c|}{ Income } \\
\hline $\begin{array}{c}<1 \text { minimum wage } \\
1 \text { minimum wage } \\
1-2 \text { minimum wages } \\
3 \text { or more minimum wages }\end{array}$ & $\begin{array}{l}2(6) \\
12(33) \\
15(42) \\
7(19)\end{array}$ \\
\hline \multicolumn{2}{|c|}{ Type of economic activity } \\
\hline $\begin{array}{c}\text { Retirees/Housewife } \\
\text { Services supply } \\
\text { Commerce } \\
\text { Healthcare } \\
\text { Food service } \\
\text { Construction } \\
\text { General administrative/business activities }\end{array}$ & $\begin{array}{l}21(58) \\
6(17) \\
3(8) \\
2(6) \\
2(6) \\
1(3) \\
1(3)\end{array}$ \\
\hline \multicolumn{2}{|c|}{ Duration of LBP complaints } \\
\hline \multicolumn{2}{|c|}{$\begin{array}{l}<1 \text { year } \\
1-5 \text { years } \\
6-10 \text { years } \\
>10 \text { years }\end{array}$} \\
\hline Radiating pain & $11(31)$ \\
\hline Use of pain medication & $30(83)$ \\
\hline \multicolumn{2}{|c|}{ Perceived initial trigger for LBP } \\
\hline $\begin{array}{l}\text { Idiopathic } \\
\text { Work } \\
\text { Accident } \\
\text { Surgery }\end{array}$ & $\begin{array}{l}18(50) \\
7(19) \\
8(22) \\
3(8)\end{array}$ \\
\hline
\end{tabular}




\begin{tabular}{cc}
\hline Pain intensity - NRS (median/IQ) & $5.50 / 4$ \\
\hline Disability - RM (mean \pm SD) & $13.19 \pm 6.95$ \\
\hline MET-minutes/week - IPAQ (median/IQ) & $1456 / 2578$ \\
\hline
\end{tabular}

BMI: Body Mass Index; IQ: Interquartile; IPAQ: International Physical Activity Questionnaire; LBP: low back pain; NRS: Numerical Rating Scale; RM: Roland Morris; SD: Standard Deviation.

Participants were classified as very active (3\%), active The median of total METs spent by the sample was 1456 (53\%), irregularly active (42\%) and sedentary (3\%) (Figure 2). MET-minutes/week.

\section{Physical Activity Levels}

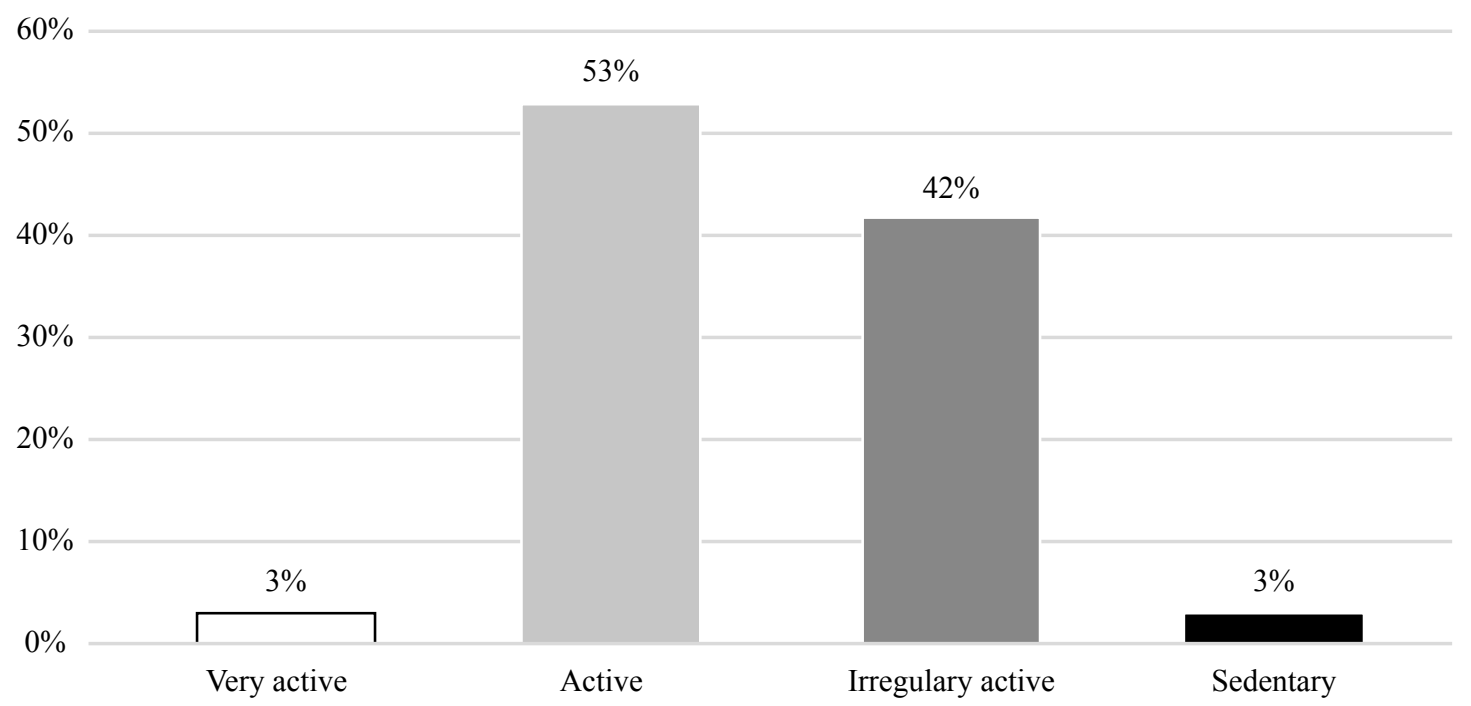

Figura 2 - Participants physical activity levels demonstrated in categories very active, active, irregularly active and sedentary, according to IPAQ short version (=36).

Physical activity levels measured in METs (IPAQ) and LBPrelated disability (RM) were moderate and negatively associated $(r=-0.45 / p=0.006)$ meaning that lower physical activity levels were associated with higher levels of disability. As to physical activity levels and pain intensity, although we found a negative correlation between variables, this correlation was of low magnitude and not statistically significant $(\mathrm{r}=-0.29 / \mathrm{p}=0.1)$.

\section{Discussion}

We performed a cross-sectional analysis of the physical activity levels and chronic LBP-related pain intensity and disability in adults suffering from this complaint. Our results indicated that even though the majority of participants were either irregularly active or active, only the minority of them was engaged in physical exercise programs. Furthermore, our findings showed that having lower physical activity levels increases LBPrelated disability.

While some studies state that people with chronic LBP have similar physical activity levels when compared with individuals without pain complaints ${ }^{18}$, others state that the type and quality of physical activity are different and these would influence the disability ${ }^{19,20}$. Spenkelink, Hutten, Hermens, Greitemann ${ }^{19}$ demonstrated in their study that subjects with chronic LBP require all their physical ability to perform tasks imposed during the day, making their physical activity level lower during the night. These authors also showed that patients with chronic LBP have oscillations while performing physical activities. This means that when compared with individuals without pain, patients with chronic LBP basically have two types of activity pattern: the first characterized by more frequent rest stops due to pain, and the second characterized by a continuous activity until it is finished, resulting in physical overload.

Importantly, we found that physical activity and disability were correlated, which contributes to the concept of the existence of an inverse relationship between physical activity and LBP disability, where low physical activity levels are related to greater disability $^{7}$. Lin, Mcauley, Macedo, Barnett, Smeets, Verbunt ${ }^{7}$ conducted a systematic review including 18 studies investigating the relationship between physical activity and LBP-related disability. Authors found the existence of a negative correlation between these factors in patients with chronic LBP only. Moreover, Ryan, Gray, Newton, Granat ${ }^{21}$ evaluated the physical activity level as an outcome measure of functional ability in people with chronic LBP. Their results demonstrated a positive correlation, 
significant and of moderate magnitude between physical activity level and functioning, showing that physically active individuals with chronic LBP had greater functional capacity.

Regarding the low frequency of participants engaged in physical exercise programs, our results are similar to previous studies that indicated that a third of adults do not comply with public health guidelines for recommended physical activity levels, showing that these are physically inactive ${ }^{22}$. Physical exercise in patients with chronic LBP was also investigated in studies by Oliveira, Salgueiro, Alfieri ${ }^{23}$ and Costa, Carvalho, Rodrigues, Battisti, Barbosa, Hamu ${ }^{24}$. Both studies analyzed the clinical and epidemiological profile of patients with chronic LBP complaints, and showed that $52.4 \%$ and $62.4 \%$ of individuals are not engaged in physical exercise regularly, and are either overweight or obese $\mathrm{e}^{21,22}$. Our results corroborate with these findings.

Indeed, being physically active seems to predict positive outcomes for those with chronic back pain complaints. Jacob, Baras, Zeev, Epstein ${ }^{25}$ demonstrated in a cross-sectional study on 2,000 Israelis adults that the practice of regular exercise was associated to a lower frequency and decrement of the severity of pain in subjects with chronic LBP. In addition to the volume of activity, the type of activity can influence the improvement or worsening of pain. A study by Hurwitz, Morgenstern, Chiao ${ }^{26}$ showed that the participation of individuals with chronic LBP in leisure physical activities and specific exercises for low back pain for 18 months seemed to be a protective factor for the manifestation and worsening of pain, disability and psychological distress, both transverse and longitudinally, while Heneweer, Staes, Aufdemkampe, Rijn, Vanhee ${ }^{27}$ showed that high demands of professional activity contributed to the increased prevalence and worsening of back pain. Such findings make us believe that being engaged in physical exercise programs bring positive results to those with chronic back pain complaints in the long term. Findings that strengthen this assumption can be observed in the study by Pinto, Ferreira, Kongsted, Ferreira, Maher, Kent ${ }^{28}$, who showed that, after one year of follow-up, people with chronic LBP who practiced leisure-time physical activity of moderate to strong intensity reported decreased pain and disability in relation to the sedentary group.

As to physical activity levels and pain intensity, our findings do not support the association between these factors. Kamada et al. ${ }^{29}$, did not find a significant association between these variables when analyzing data from a cohort study on 4,559 Japanese adults with chronic LBP. Hendrick et al. ${ }^{5}$ also investigated the relationship between physical activity levels, pain and disability in patients with chronic LBP and showed that present evidence does not support a relationship between physical activity levels and the pain intensity. When analyzing 12 studies selected for their systematic review, they only found one prospective study reporting a statistically significant relationship between increased leisure activity and improvements in pain intensity, and one cross-sectional investigation indicating lower levels of sports activity associated with higher levels of pain and disability. The remaining studies $(n=10)$ found no relationship between the variables investigated.

We understand that our study has limitations. First, the IPAQ does not discriminate different physical activities in contributing to participants being more or less active. Besides, its self-report nature allows patients minimizing or exaggerating the amount of physical activity performed. However, the IPAQ was shown to be affordable for being low cost and easy to apply, being relevant within the context of the sample of the study. Second, the small sample size prevented us from conducting more robust analysis that could have shown other factors related to being physically active in those with LBP at Primary Health Care. However, this is a preliminary study, part of a larger ongoing research, conducted in a low income area of a city in the Northeast of Brazil, in which studies of this nature are currently being developed. To our knowledge, this is the first study investigating physical activity and LBP disability in this scenario.

Our results are in context with an important health issue being broadly discussed, which is physical inactivity. Physical inactivity has become pandemic since, nowadays, sedentary behavior is becoming more prevalent, bringing significant financial and social burden for the society ${ }^{8,30}$. In Brazil, for example, of the total number of hospitalizations in 2013 by the Brazilian Unified Health System (SUS), 15\% was attributed to physical inactivity, resulting in a total estimated cost of $\mathrm{R} \$$ 275.646.877.64 (US\$ 8.591.454.674,43) ${ }^{31}$. Considering the benefits already known of physical exercises on physical and mental health and social life of the population in general, we believe it is necessary to investigate and furthermore implement interventions that aim not only to increase the physical activity level in patients with chronic LBP, but also encouraging these patients to be involved in physical exercise programs. Future studies should aim at targeting physical activity assessment with objective measures and larger sample sizes investigating community-based patients with LBP.

\section{Conclusion}

Our findings show that the majority of participants were either active or irregularly active. In contrast, most individuals with chronic LBP mostly did not engage in regular physical exercise programs. Lower physical activity levels were associated with higher levels of disability, but not with pain intensity. The observational nature of this study prevent us from pointing to directions towards intervening in these patients; still, our findings reinforce previous findings advocating that interventions encouraging increments in physical activity levels in them may be an important ally to manage this condition. Future research should be conducted to explore which type of activity is more positively associated with functional gains in them.

\section{References}

1. Souza CS, Oliveira AS. Prevalência de encaminhamentos às doenças musculoesqueléticas segundo a classificação estatística internacional de doenças (CID-10): reflexões para formação do fisioterapeuta na área de musculoesquelética. Fisioter Pesq. 2015; 22 (1): 48-53.

2. Leopoldino AAO, Diz JBM, Martins VT, Henschke N, Pereira LSM, Dias RC, et al. Prevalence of low back pain in older 
Brazilians: a systematic review with meta-analysis. Rev Bras Reumatol. 2016; 56 (4): 258-269.

3. Toscano JJO, Egypto EV. A influência do sedentarismo na prevalência de lombalgia. Rev Bras Med Esporte. 2011; 7 (4): 132-137

4. Heneweer H, Vanhees L, Picavet HS. Physical activity and low back pain: a U-shaped relation? Pain. 2008; 143 (1): 21-5.

5. Hendrick P, Milosavljevic S, Hale L, Hurley DA, Mcdonough S, Ryan B, et al. The relationship between physical activity and low back pain outcomes: a systematic review of observational studies. Eur Spine J. 2011; 20 (3): 464-474.

6. Leeuw M, Goossens ME, Linton SJ, Crombez G, Boersma K, Vlaeyen JW. The fear-avoidance model of musculoskeletal pain: current state of scientific evidence. J Behav Med. 2007; 30: 77-94

7. Lin CWC, Mcauley JH, Macedo L, Barnett DC, Smeets RJ, Verbunt JA. Relationship between physical activity and disability in low back pain: A systematic review and meta-analysis. Pain. 2011; 152 (3): 607-613.

8. Kohl 3rd HW, Craig CL, Lambert EV, Inoue S, Alkandari JR, Leetongin $\mathrm{G}$, et al. The pandemic of physical inactivity: global action for public health. Lancet. 2012; 380: 294-305.

9. Cohen J. Statistical power analysis for the behavioral sciences. 2nd ed. Hillsdale, NJ: Lawrence Erlbaum Associates; 1988.

10. Nachemson AL. The lumbar spine: na orthopedic challenge. Spine. 1976; 1 (1): 59-71.

11. World Health Organization [http://www.who.int]. Global Recommendations on Physical Activity for Health. 2011. Available at: http://www.who.int/dietphysicalactivity/physicalactivity-recommendations-18-64years.pdf.

12. Hallal PC, Gomez LF, Parra DC, Lobelo F, Mosquera J, Florindo AA, et al. Lições Aprendidas Depois de 10 Anos de Uso do IPAQ no Brasil e Colômbia. J Phys Act Health. 2010; 7 (2): 259-264.

13. Matsudo SM, Araújo T, Matsudo VR, Andrade D, Andrade E, Oliveira LC, Braggion G. Questionário Internacional De Atividade Física (Ipaq): Estudo de Validade e Reprodutibilidade No Brasil. Rev. bras. ativ. fís. saúde. 2001; 6 (2): 5-1

14. Matsudo SM, Matsudo VR, Araújo T, Andrade D, Andrade E, Oliveira L, et al. Nível de atividade física da população de São Paulo: análise de acordo com gênero, idade, nível socioeconômico, distribuição geográfica e de conhecimento. Rev. Bras. Ciênc. e Mov. 2002; 10 (4): 41-50.

15. Guidelines for data processing and analysis of the International Physical Activity Questionnaire (IPAQ)-Short and Long Forms. Retrieved from http://www.ipaq.ki.se/scoring.pdf. 2005.

16. Nusbaum L, Natour J, Ferraz MB, Goldenberg J. Translation, adaptation and validation of the Roland-Morris questionnaire Brazil Roland-Morris. ¡Braz. J. Med. Biol. Res. 2001; 34 (2): 203-210.

17. Andrade FA, Pereira LV, Sousa FAEF. Mensuração da dor no idoso: uma revisão. Rev Latino-am Enfermagem. 2006; 14 (2): 271-176.

18. Van Weering M, Vollenbroek-Hutten MMR, Kotte Roessingh MMR, Hermens HJ. Daily physical activities of patients with chronic pain or fatigue versus asymptomatic controls. A systematic review. Clin Rehabil. 2007; 21 (11): 1007-1023.

19. Spenkelink CD, Hutten MMR, Hermens HJ, Greitemann BOL. Assessment of activities of daily living with an ambulatory monitoring system: a comparative study in patients with chronic low back pain and nonsymptomatic controls. Clin Rehabil. 2002; 16 (1):16-26.
20. Huijnen IP, Verbunt JA, Roelofs J, Goossens M, Peters M. The disabling role of fluctuations in physical activity in patients with chronic low back pain. Eur J Pain. 2009; 13 (10): 1076-1079.

21. Ryan CG, Gray H, Newton M, Granat MH. The convergent validity of free-living physical activity monitoring as an outcome measure of functional ability in people with chronic low back pain. J Back Musculoskelet Rehabil. 2008; 21 (2): 137-142.

22. Hallal PC, Andersen LB, Bull FC, Guthold R, Haskell W, Ekelund U, for the Lancet Physical Activity Series Working Group. Global physical activity levels: surveillance progress, pitfalls, and prospects. Lancet. 2012; 380: 247-57.

23. Oliveira JG, Salgueiro MMHAO, Alfieri FM. Lombalgia e Estilo de Vida. Cient Ciênc Biol Saúde. 2014. 16 (4): 341-4.

24. Costa MC, Carvalho FM, Rodrigues WCC, Battisti L, Barbosa AM, Hamu TCDS. Perfil epidemiológico e clínico dos pacientes com queixa de dor lombar atendidos em uma clínica escola de fisioterapia. Movimenta. 2015; 8 (1): 37-42.

25. Jacob T, Baras M, Zeev A, Epstein L. Physical Activities and Low Back Pain: A Community-Based Study. Med. Sci.Sports Exerc. 2004; 36 (1): $9-15$.

26. Hurwitz EL, Morgenstern H, Chiao C. Effects of Recreational Physical Activity and Back Exercises on Low Back Pain and Psychological Distress: Findings From the UCLA Low Back Pain Study. Am J Public Health. 2005, 95 (10): 1817-1824.

27. Heneweer H, Staes F, Aufdemkampe G, Rijn MV, Vanhees L. Physical activity and low back pain: a systematic review of recent literature. Eur Spine J. 2011; 20 (6): 826-845.

28. Pinto RZ, Ferreira PH, Kongsted A, Ferreira ML, Maher CG, Kent P. Self-reported moderate-to-vigorous leisure time physical activity predicts less pain and disability over 12 months in chronic and persistent low back pain. Eur J Pain. 2014; 18 (8): 1190-1198.

29. Kamada M, Kitayuguchi J, Lee IM, Hamano T, Imamura F, Inoue $\mathrm{S}$, et al. Relationship between physical activity and chronic musculoskeletal pain among community-dwelling Japanese adults. J Epidemiol. 2014; 24 (6):474-83.

30. Reis RS, Salvo D, Ogilvie D, Lambert EV, Goenka S, Brownson RC. for the Lancet Physical Activity Series 2 Executive Committee. Scaling up physical activity interventions worldwide: stepping up to larger and smarter approaches to get people moving. Lancet. 2016; 388: 1337-48.

31. Bielemann RM, Silva BG, CollCde V, Xavier MO, Silva SG. Burden of physical inactivity and hospitalization costs due to chronic diseases. Rev. Saúde Públ. 2015; 49: 1-8.

\section{Corresponding author}

Fabianna Resende de Jesus-Moraleida

Universidade Federal do Ceará, Centro de Ciências da Saúde.

Rua Alexandre Barúna, 949, Rodolfo Teófilo, Fortaleza, CE, Brazil

Email: fabiannamoraleida@gmail.com

Manuscript received on November 22, 2016

Manuscript accepted on February 22, 2017

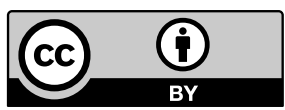

Motriz. The Journal of Physical Education. UNESP. Rio Claro, SP, Brazil - eISSN: 1980-6574 - under a license Creative Commons - Version 3.0 